\title{
WAYS TO IMPROVE THE SYSTEM OF MEDICAL PROVIDING OF PUPILS IN UKRAINE
}

10.36740/WLek202010130

\author{
Tatiana V. Peresypkina ${ }^{1,2}$ \\ 'STATE INSTITUTION “INSTITUTE FOR CHILDREN AND ADOLESCENTS HEALTH CARE OF THE NATIONAL ACADEMY OF MEDICAL SCIENCES OF UKRAINE”, \\ KHARKIV, UKRAINE \\ 2V. N. KARAZIN KHARKIV NATIONAL UNIVERSITY, KHARKIV, UKRAINE
}

\begin{abstract}
The aim: Of this article was analysis of the existing health care system for school-age children in Ukraine and the identification of ways to improve and develop the school health care system like a topical issue of pediatrics.

Materials and methods: The analysis of the state of health of children in Ukraine, the questionnaire of the participants of the educational process regarding the expedient and expected types of medical care, the WHO publications on the medical provision of schoolchildren were analyzed.

Conclusions: The analysis of the legal framework in Ukraine in the period of reforming the medical sector has allowed to identify the problematic issues, the solution of which will contribute to ensuring the quality of the medical aid system for school-age children, improving the level of health, shaping the health behavior of health behavior. These include improving the legal framework on some issues, defining the functional authority and structure of the school health care system.
\end{abstract}

KEY WORDS: medical care for children, standard of medical care

Wiad Lek. 2020;73(10):2261-2264

\section{INTRODUCTION}

Data of health indicators of the Health Statistics Center of the Ministry of Health of Ukraine [1] indicate that the health of children and adolescents in Ukraine still does not have a stable dynamic for changes for the better. The prevalence of the disease in the children population remains high, especially among adolescents aged 15-17. Thus, for the period $2001-2017$, the prevalence of diseases among adolescents increased by $46.6 \%$ (from $1485.7 \%$ in 2001 to $2177.7 \%$ in 2017). The most common classes of diseases are: diseases of respiratory system; digestive diseases; the eye and the appendix; endocrine system, eating disorders and metabolic disorders; musculoskeletal system and connective tissue; nervous system.

This situation requires immediate action to improve the health care system for children and adolescents.

Considering the long stay of children in educational establishments, WHO emphasizes that today, the educational institution is called to perform not only educational function but also take care of the health of children. A school cannot exist without a health care system, and the health care of students must be tightly integrated into the education system.

Therefore, the analysis of the existing health care system for school-age children in Ukraine and the identification of ways to improve and develop the school health care system becomes a topical issue of pediatrics.

\section{THE AIM}

The aim of this article was analysis of the existing health care system for school-age children in Ukraine and the identification of ways to improve and develop the school health care system like a topical issue of pediatrics.

\section{MATERIALS AND METHODS}

Analysis of data from the Health Statistics Center of the Ministry of Health of Ukraine on the health status of the children population, literary sources on medical care for children of school age, result of questionnaires of participants in the educational process regarding types of medical care for children in school.

\section{REVIEW AND DISCUSSION}

Today, Ukraine is following the path of reforming the medical sector. In accordance with the legal framework, the medical provision for students of educational institutions is changing. The Law on General Secondary Education stipulates that "... pupils (students) of general secondary education institutions, regardless of their subordination, types and forms of ownership, are provided with medical care provided by medical staff who are members of these institutions..."[2]. Decree of the Cabinet of Ministers of Ukraine of December 8, 2009 N 1318 "The procedure of 
providing medical care for students of secondary schools" stipulates that medical care includes, among other things, "the implementation of preventive and health measures during training, emergency medical care.... »[3].

However, in the period of reforming the industry, against the background of some ambiguity of the regulatory framework, a number of organizational problems regarding the medical provision of schoolchildren were identified. According to the current regulatory framework, the functions of such units of children's polyclinics as "school-preschool departments" are lost today and the medical care for children in the educational institution is provided by the average medical worker, who is already is a employee of the educational organization. According to the current legislation, after medical examinations of students in health care facilities, the child is provided with appropriate recommendations for additional examination, or for other medical, preventive and rehabilitation measures. In a situation where the medical staff at the educational institution is no longer subordinate to the children policlinics; does the connection between the medical facility and the healthcare provider of the educational institution lose in this case? Will the school health professional have timely information on the results of the child's medical examination?

The question remains, where all the information about the students' health, the results of the medical examinations, their quality and the quality of implementation of the recommendations are accumulated. This is especially important against the background of the reform of the sanitary and epidemiological service, when the function of accumulation, monitoring and analysis of information of the health of the younger generation, comparison of data within educational collectives, educational establishments, and among city institutions is almost lost.

Also, according to the medical examinations, it is advisable to carry out sanitary and educational work on the prevention of diseases with students and parents, to bring the results of medical examination to the pedagogical staff of the school and parents. And is there enough experience and knowledge on the average healthcare professional? Maybe they need the help of doctors or other professionals, stakeholders?

In the context of leaving secondary school health professionals loss the control by health care facility, it is necessary to clearly identify ways of obtaining information about the epidemiological situation among children of educational institutions in the area of school location, who will provide examination and control of contact children (including a doctor) in connection with quarantine measures. Topical issues are increasing their competence and updating their knowledge of physiology and pathology of childhood.

As a positive point, it can be defined that now the average health worker, who is subordinate to the ministry of Education, always works in the mode that is appropriate for the institution, the health worker is in the institution all the time, they can be involved in extra-curricular activities.

For many years, the State Institution "Institute for chil- dren and adolescents health care of the National Academy of Medical Sciences of Ukraine" has been responsible for the problems of preserving the health of children and the issues of medical care for students.

Thus, seminars for doctors providing medical assistance to children in the general educational institutions - "Day of the school doctor and teenage therapist" are held on the basis of the State Institution of the Institute of Medical Sciences of the National Academy of Medical Sciences during the period of existence of the Institute. In recent years, when medical care for children provided by nurse similar monthly seminars have been introduced for mid-level professionals.

With considerable experience in affecting the health of the younger generation, identifying the factors that shape it, as well as the experience of applying this knowledge in practice. The Institute's specialists fruitfully collaborate with educators, extending their experience to pedagogical staff of district or city methodologist, making speeches to others actual medical topics about health care for directors, educators of the city and region, according to inter-sectoral interaction measures.

As a result, the joint efforts of such intersectoral cooperation, it is possible to solve the issues of increasing the level of skills and knowledge regarding the formation of healthy lifestyles of schoolchildren, improving the competencies of medical staff of educational institutions, determining the types of medical care required for schoolchildren.

Thus, the conducted research among all participants of the educational process (teachers and heads of educational institutions, parents, medical workers) regarding the expedient and necessary types of medical care in the secondary education institution showed that among the important sections of work, according to educators and medical professionals, there are involvement of a medical professional in working with parents, conducting anti-epidemic measures, control of nutrition, rendering of first aid, control of organization of physical education, control of sanitary-hygienic regime, conducting wellness events for children with chronic diseases, monitoring health status. At the same time, less attention is paid by directors and educators, compared to medical staff, to outpatient admission and holding of wellness events in an educational setting.

That is, teachers and heads of educational institutions do not see any point in conducting medical rehabilitation work with schoolchildren. Instead, parents expect the health care provider to help the child with any complaints and look forward to receiving help in the event of an emergency. Only a third of parents consider it advisable to carry out sanitary and educational work in an institution.

In the context of reforming such a vital sector of the country as healthcare, it is advisable to rely on international, science-based experience in the provision of medical care for children in educational settings.

According to WHO sources, an effective health care system for children in educational institutions has not yet been identified. The system of school health professionals is doctors, psychologists, nutritionists, social workers, 
and more. However, nurse is the leading figure in school medicine in most countries. [4].

The WHO European Office, together with the European Union for School and University Medicine (EUSUHM), has developed the "European Concept for Quality of School Health Services and Competences for School Health Professionals" [5], which is recommended for use by all interested countries after adapting it to the needs of the country.

The concept includes the standards of the school health care system and a core set of competencies covering seven groups of functions. That is, the school medical officer is at the same time: expert of the school medical services system, communicator, and organizer of interagency cooperation, manager of medical services, organizer of health information, scientist (self-improvement and analysis of scientific information), specialist (who acts accordingly to international and national regulations act). The competences are quite diverse and are designed for a person or a team with deep knowledge in the field of medicine (knowledge of the physiology of growth and development of the child, factors affecting his health), in the field of psychology (motivation, persuasion, communication), in the field of administration (management, management, or administrative management).

The standards proposed in the Concept are intended to help policy makers, at the State or local levels, to provide the highest quality school health care services.

Seven reference Standards and ancillary characteristics are proposed, the analysis and adherence of which will help to identify the existing weaknesses in health care in the country and to develop ways to improve it.

An analysis was made of the health care service for secondary school students in the period of reforming the health care industry in accordance with the Standards set out in the WHO Concept and identifying ways of solving problems.

Standard 1: Ensuring the legal protection of the health of children and adolescents, taking into account the national legal framework;

- Legislative acts, concerning the types of interaction between medical workers of educational establishments and specialists of primary level of health protection, the process of transfer of documentation of teenage children to medical-preventive institution for adults are subject to improvement;

- The functional responsibilities and competencies of health care providers who provide health care in educational institutions, their interaction and subordination with other structures and organizations, including medical institutions are clarification requires;

- The algorithm for collaboration between medical workers of educational establishments and specialists of primary level of health protection for provide rehabilitation measure or preventive work after preventive examinations in education facilities are requires to development;

- Develop an effective monitoring scheme for students' health and develop preventative measures to prevent health disorders, interact with other institutions and institutions as needed;

Standard 2: Adherence to the principles of high quality required for school health services, accessibility; social justice; continuity in providing medical assistance to students and educators;

- It is necessary to substantiate the algorithm of cooperation of medical workers of educational institutions of general secondary education with specialists of primary health-care unit, other institutions, their subordination;

- For provide educational information on HLS formation and to preventing of development of noncommunicable diseases, use different ways and methods, namely: to involve the health care provider (nurse) in the educational process (like in lessons in the basics of health, etc.) or other health education activities as competent specialist of school medical care;

- On the basis of a clear definition of the competences of all participants of the educational process, to provide the full range of necessary medical services in the educational institution.

Standard 3: Equipment, incl. computer and staffing for the school health service;

- For provide effective monitoring of the state of health of pupils and to evaluate result of preventive measures make ability to free access to computer equipment, the Internet for the purpose of raising the level of knowledge, cooperation with specialists of different profiles;

- A clearer definition is required of normative documents on logistical and medicines, which can use in general secondary education institutions;

- Determine the action algorithm forincrease qualification level of medical staff in education facilities in the conditions of change of departmental subordination;

Standard 4: Interaction of school health professionals with the administration of the school, teachers, parents and children on maintaining and promoting the health of children at school with clear definition of authority;

- school health workers have complete information about children's health, their needs for preventive measures at the level of educational institution, regular proof of this information to the administration, parents, teachers, which is enshrined in the relevant regulatory documents;

- Determination of the authority of the medical officer in the educational institution to participate in the planning of educational activities for the formation of HLS with schoolchildren, parents, participation of the medical worker in these activities.

Standard 5: Staff have clearly defined job responsibilities, adequate knowledge and skills, and commitment to adherence to quality standards for school health services;

- Establish, at the legislative level, the link between educational institutions and medical institutions of postgraduate education (as specialized in education) regarding the possibility of upgrading the qualification and postgraduate training of medical staff in educational institutions and which are subordinate to educational institutions (tuday are full-time employees of educational establishments); 
- It is necessary to clearly define the duties of medical professionals in the absence of a license to conduct medical activities in educational institutions;

- Define clear quality standards for the provision of school medical services;

- Identify at the legislative level the main facilities that coordinates the activities of school health systems;

Standard 6: Definition of a school health care package based on public health priorities, supported by science-based child health protocols

- Today, educational institutions are not licensed to provide medical assistance to students, so a clear definition of the school services package is required;

- Determine the feasibility and appropriateness of conducting rehabilitation activities for children with chronic pathology or special medical needs in the education establishment;

Standard 7: Establishing a data management system that meets the standards for the protection of personal data of children and adolescents, and at the same time, allows provide monitor of health of students by certain criteria and indicators.

In the conditions of reforming the system of sanitary-epidemiological service and school-preschool departments of medical-prophylactic establishments, there is absent medical establishment that has a fully real data regarding the health status of school-age children, their sanitary-epidemiological provision in the conditions of educational institution, in respect of observance rules and regulations. This function should be assigned to the research institutions of the National Academy of Medical Sciences, taking into account their years of experience.

Thus, the problem of bringing the existing system of medical care for schoolchildren in Ukraine to the recommended WHO standards can be solved by improving the legal framework, defining the basic institution and its authority to coordinate the activities of school health professionals (as the most appropriate - a scientific institution with a positive experience in this area. And the setting up a unit or possibly expanding the functions of public health centers at local and regional levels with a clear definition of their functional powers to coordinate the activities of school health care providers at district, local levels and to cooperate with the basic state institution, other health care institutions, academies of medical sciences, public organizations, etc. on health monitoring, developing healthy lifestyle skills, prevention of non-communicable diseases.

\section{CONCLUSIONS}

The negative dynamics of changes in the prevalence of diseases among the children population requires immediate changes in the system of medical care in education facilities. The ideal international model of health care for general secondary school students has not yet been identified.
It is advisable to take the WHO recommended "European Concept for Quality of School Health Services and Competences for School Health Professionals" as a basis for reforming the health care system for school-age children.

Weaknesses were identified regarding the conformity of the Ukrainian realities of medical provision of schoolchildren in the period of reforming the industry to the WHO standards of quality of care for school-age children: imperfection of the legal and regulatory framework, determination of functional powers and structure of the school health care system. These problems need to be addressed as soon as possible.

\section{REFERENCES}

1. Health status of children and adolescents of Ukraine. Center for Medical Statistics of the Ministry of Health of Ukraine. http://medstat.gov.ua/ ukr/main.html

2. The Law on General Secondary Education in Ukraine. 16.01.2020 №463IX. https://zakon.rada.gov.ua/laws/show/651-14.

3. Decree of the Cabinet of Ministers of Ukraine of December 8, $2009 \mathrm{~N}$ $1318^{\prime \prime}$ The procedure of providing medical care for students of secondary schools". https://zakon.rada.gov.ua/laws/show/1318-2009-\%D0\%BF

4. Baltag V., Levi M. Pairing Children with Health Services: The results of a survey on school health services in the WHO European Region. Copenhagen: WHO Regional Office for Europe. 2010.

5. European framework for qualitystandards in school health servicesand competences for school healthprofessionals. 2014. http://www.euro. who.int/ru/health-topics/Life-stages/child-and-adolescent-health/ publications/2014/european-framework-for-quality-standardsin-school-health-services-and-competences-for-school-healthprofessionals

\section{ORCID and contributionship:}

Tatiana. V. Peresypkina: 0000-0003-3408-1091 A, B, D, E, F

\section{Conflict of interest:}

The Author declare no conflict of interest

\section{CORRESPONDING AUTHOR}

\section{Tatiana. V. Peresypkina}

Institution "Institute for children and adolescents

health care of the National Academy of Medical Sciences of Ukraine"

52 A Jubileyny Avenue, 61052 Kharkiv, Ukraine

tel: +38 (050) 6898765,

e-mail: tatyanaiozdp@gmail.com

Received: 23.10 .2019

Accepted: 07.08.2020

A - Work concept and design, B - Data collection and analysis, C - Responsibility for statistical analysis, D-Writing the article, $\mathbf{E}$-Critical review, $\mathbf{F}$ - Final approval of the article 